\title{
Detecção de cicatrizes de áreas queimadas baseada no modelo linear de mistura espectral e imagens índice de vegetação utilizando dados multitemporais do sensor MODIS/TERRA no estado do Mato Grosso, Amazônia brasileira
}

\author{
Liana Oighenstein ANDERSON ${ }^{1}$, Luiz Eduardo Oliveira e Cruz de ARAGÃO ${ }^{2}$, André de LIMA ${ }^{1}$, Yosio \\ Edemir SHIMABUKURO ${ }^{1}$
}

\begin{abstract}
RESUMO
O objetivo desta pesquisa foi avaliar os dados do sensor MODIS para detectar e monitorar cicatrizes de áreas recém queimadas. Utilizamos imagens da reflectância de superfície do sensor MODIS: produto MOD09 (dia 5 de outubro) e produto MOD13A1 (meses de outubro e novembro). Foi avaliada também uma série temporal de um ano dos índices de vegetação (IV) EVI e NDVI (produto MOD13A1). Uma imagem do sensor ETM + (dia 5 de outubro) foi utilizada como base para a delimitação dos polígonos amostrais e avaliação dos dados MODIS devido a sua melhor resolução espacial. A metodologia focou na aplicação do modelo linear de mistura espectral nas imagens reflectância para a geração das imagens fração sombra. Análises de regressão foram efetuadas para comparação entre o percentual de sombra derivado da imagem ETM + e das imagens MODIS. As alterações multitemporais nas imagens IV foram avaliadas com base no teste de Tukey. Os resultados mostraram que a imagem fração sombra gerada a partir do produto MOD09 apresentou um $\mathrm{R}^{2}=0,66(\mathrm{p}<0,01)$ em relação aos dados ETM +. Para as imagens do produto MOD13A1 não foram identificadas relações significativas. Os IV dentro dos mesmos polígonos apresentaram uma variação sazonal durante o ano. No entanto, não houve uma diminuição significativa dos valores destes índices nos meses onde foram observadas as cicatrizes de áreas recém queimadas. Portanto, o produto MOD09 mostrou-se mais eficiente que o produto MOD13A1 para a detecção de cicatrizes de áreas recém queimadas. A análise multitemporal dos IV sugeriu que não foi possível detectar este mesmo padrão na área de estudo.
\end{abstract}

PALAVRAS CHAVE

sensor MODIS, áreas queimadas, imagens fração.

\section{Burn scar detection based on linear mixture model and vegetation indices using multitemporal data from MODIS/ TERRA sensor in Mato Grosso State, Brazilian Amazon}

\begin{abstract}
The aim of this research was to evaluate the MODIS sensor data to detect and monitor recent burned scars areas. We used MODIS sensor surface reflectance images, including: MOD09 product (October $5^{\text {th }}$ ) and MOD13A1 product (October and November). We also used one year temporal series of the vegetation indices (VI) EVI and NDVI (MOD13A1 product) to evaluate its capability to detect recent burned scars areas. An ETM+ sensor image $\left(\right.$ October $\left.5^{\text {th }}\right)$ was used as basis for the samples polygons design and to evaluate the MODIS data due to its higher spatial resolution. The methodology focused on the application of a linear spectral mixing model on the reflectance images to generate the shade fraction. Regression analyses were carried out for the comparison between the shade percentage derived from the ETM+ image and the MODIS images. The multitemporal change detection over the $V I$ images were evaluated based on the Tukey test. The results showed that the shade fraction image derived from the MOD09 product presented a $R^{2}=0,66(p<0,01)$ with the ETM + . For the MOD13A1 product images were not found a significant relationship. The VIover the same samplespolygons presented seasonal variations during the year. Even though, was not observed a significant decrease in their values on the months that we detect the burned scars. We conclude that the MOD09 product was more efficient than the MOD13A1 product to detect burn scars. The multitemporal analysis of the VI suggested that it is not possible to detect this same pattern over the study area.
\end{abstract}

\section{KEYWORDS}

MODIS sensor, burned areas, fraction images.

1Instituto Nacional de Pesquisas Espaciais - INPE. Caixa Postal 515 - 12201-970 - São José dos Campos - SP, Brasil, \{liana,yosio,andre\}@ltid.inpe.br 2University of Oxford, School of Geography and the Environment. Mansfield Road Oxford OX13TB, United Kingdom. luiz.aragao@ouce.ox.ac.uk 


\section{ACTA \\ AMAZONICA}

DETECÇÃO DE CICATRIZES DE ÁREAS QUEIMADAS BASEADA NO MODELO LINEAR DE MISTURA ESPECTRAL E IMAGENS ÍNDICE DE VEGETAÇÃO UTILIZANDO DADOS MULTITEMPORAIS DO SENSOR MODIS/TERRA NO ESTADO DO MATO GROSSO, AMAZÔNIA BRASILEIRA

\section{INTRODUÇÃO}

A queima de biomassa afeta diretamente o ciclo do carbono pois perturba a química atmosférica global através da liberação de gases de efeito estufa e aerossóis (Page et al., 2002; Sá et al., 2003; Sousa et al., 2003). Os processos de mudanças na cobertura vegetal, tanto a partir de causas antrópicas quanto de processos naturais, representam um papel central nas emissões de carbono nos trópicos. O principal gás de efeito estufa é o $\mathrm{CO}_{2}$ (dióxido de carbono) (Lashof, 1996) quecompõe aproximadamente $90 \%$ das emissões de gases liberados durante as queimadas (Levine et al., 1996). Esta liberação de carbono para a atmosfera causa um impacto direto nas trocas radiativas na superfície, causando mudanças no clima global. Segundo Grace (2004), cerca de 60\% do aquecimento global é atribuído a elevação da concentração de $\mathrm{CO}_{2}$ na atmosfera. As estimativas mais recentes de emissão de $\mathrm{CO}_{2}$ devido à conversão de florestas e abadono de terras cultivadas mostram que a Amazônia brasileira contribui com cerca de $2 \%$ do total anual de carbono emitido no planeta devido à forcantes antrópicas (IPCC, 1996; MCT, 2004).

Uma das variáveis cruciais para quantificar a magnitude da queima de biomassa em escala global, é o tamanho da área afetada. Para determinação desta variávelé necessária a utilização de dados oriundos de sensores remotos, que permitem o monitoramento temporal e a espacialização destes eventos (Grégoire et al., 2003).

Existem duas linhas de pesquisas relacionadas à detecção e monitoramentos dos eventos de queimadas: a primeira referese à deteç̧ão dos focos de calor, geralmente associada a fogos ativos, que utiliza as bandas espectrais da região do infravermelho termal (Justice et al., 2002, Giglio et al., 2003, Pergola et at., 2004, Li et al., 2005). A segunda linha está relacionada à espacialização das queimadas. Esta concentra-se na quantificação da extensão das áreas afetadas por este evento, geralmente utilizando bandas espectrais da região do visível e/ ou associadas as bandas espectrais da região do infra-vermelho termal (Pereira e Setzer, 1996, Domenikiotis et al., 2002, Roy et al., 2002, Stoppiana et al., 2003, Gitas et al., 2004, Silva et al., 2005).

As incertezas relacionadas a detecção e ao monitoramento das áreas queimadas vem sendo discutidas na literatura em relação as possíveis causas destes erros. Por exemplo, o sensor AVHRR (Advanced Very High Resolution Radiometer) é um dos sensores de baixa resolução espacial mais utilizado para a detecção e monitoramento de queimadas dada sua alta resolução temporal. No entanto, Pereira e Setzer (1996) discutiram a problemática da superestimativa de área queimada devido ao baixo limiar de saturação da banda $3(3.550$ - 3.930 $\mathrm{nm}$ ) do sensor AVHRR, que pode gerar confusão com a resposta espectral de fogos ativos. Lombardi (2003) combinando uma análise visual com mudanças espectro-texturais, em imagens do sensor TM (Thematic Mapper) do satélite Landsat, concluiu que a utilização de um sensor com maior resolução temporal poderia permitir um aumento da exatidão no monitoramento desses fenômenos. O monitoramento deste processo em regiões como a Amazônia, que além da extensão da territorial é agravado pela alta taxa de cobertura de nuvens, exige a utilização de sensores com alta resolução temporal, aliados à técnicas de processamentos de imagens. Por exemplo, uma alternativa para a detecção e monitoramento de queimadas em regiões que possuem alta taxa de cobertura de nuvens é a utilização de imagens NDVI, geralmente utilizados na forma de mosaicos (Pereira, 1999, Domenikiotis et al. 2002).

Com o lancamento dos satélites Terra e Aqua portando o sensor MODIS (Moderate Resolution Imaging Spectroradiometer), em 1999 e 2002, respectivamente, iniciouse uma nova perspectiva para o monitoramento e detecção de queimadas (Justice et al.,2002, Roy et al., 2002, Zhan et al., 2002).

Este sensor possui uma série de características melhoradas em relação aos sistemas do NOAA/AVHRR (National Oceanic Atmospheric Administration) e do GOES (Geostationary Operational Environmental Satellite), como por exemplo, uma melhor resolução espectral e radiométrica (Justice et al., 2002). Além disso, apresenta também uma melhor resolução espacial nas bandas espectrais da região do visível em relação aos sensores de baixa resolução espacial, como AVHRR e o SPOTVEGETATION. Aliado a estas características, o sensor MODIS apresenta uma alta resolução temporal (1-2 dias).

A utilização de imagens fração derivadas da aplicação do MLME (Modelo Linear de Mistura Espectral) vem apresentando bons resultados para estudos de deteç̧ão de desmatamentos (Anderson et al., 2005), áreas degradadas (Almeida-Filho e Shimabukuro, 2002), estágio de sucessão em florestas plantadas (Sabol et al., 2002) e caracterização de centros urbanos (Samall, 2003). Estes trabalhos partem do princípio que com base na resposta espectral de alvos puros (endmenbers) selecionados para a geração do modelo, é possível extrair na forma de imagens sintéticas as feições ressaltadas dos alvos desejados, facilitando sua detecção e monitoramento.

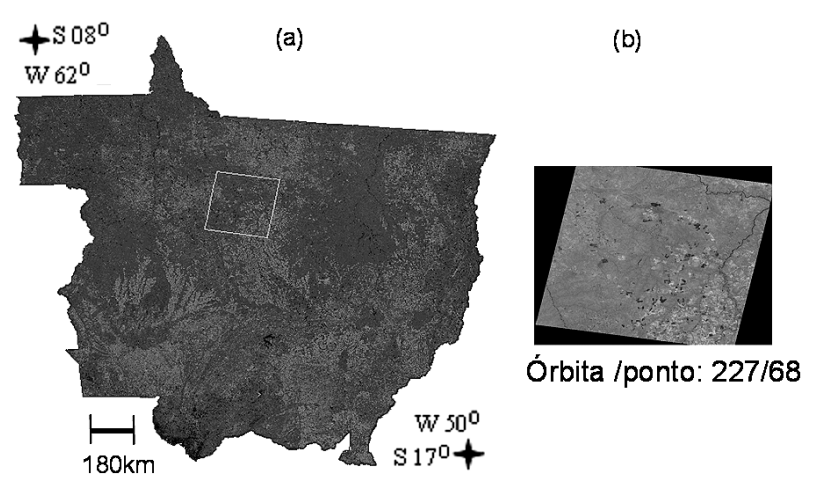

Figura 1 - Localização da área de estudo. (a) Estado Mato Grosso, localizado na Região Centro-oeste do Brasil; (b) Área de validação correspondente à cena ETM+ (227/68). 


\section{ACTA \\ AMAZONICA}

DETECÇÃO DE CICATRIZES DE ÁREAS QUEIMADAS BASEADA NO MODELO LINEAR DE MISTURA ESPECTRAL E IMAGENS ÍNDICE DE VEGETAÇÃO UTILIZANDO DADOS MULTITEMPORAIS DO SENSOR MODIS/TERRA NO ESTADO DO MATO GROSSO, AMAZÔNIA BRASILEIRA
Assim, para esta pesquisa foram elaboradas as seguintes hipóteses:

a) Dada a similaridade entre a resposta espectral das cicatrizes de áreas recém queimadas e de alvos de sombras (baixo valor de reflectância em todas as bandas espectrais), 0 uso das imagens fração sombra derivadas do modelo linear de mistura, quando aplicado a imagens de reflectância diária (MOD09) e mosaicos de 16 dias (MOD13A1) do sensor MODIS, possibilitam a caracterização dessas feições.

b) Devido a elevada taxa de cobertura de nuvens na Amazônia, sugere-se o uso de mosaicos combinando imagens de várias datas, que devem apresentar a mesma capacidade de caracterização de cicatrizes de áreas recém queimadas que a imagem diária.

c) Devido a dinâmica temporal das queimadas, o uso de séries temporais de imagens índice de vegetação (MOD13A1) permitem a detecção do período de ocorrência desses eventos.

Para testar estas hipóteses, esta pesquisa teve como objetivo geral avaliar o comportamento espectral das cicatrizes de áreas queimadas nas imagens diárias e em composições mensais do sensor MODIS. Para testar a primeira hipótese, a distribuição de freqüência dos valores da fração sombra das imagens ETM+ (Enhanced Thematic Mapper), MOD09 e MOD13A1 foi comparada com os valores das frações solo e vegetação nas áreas com cicatrizes recentes de queimadas. Com o objetivo de testar a segunda hipótese, os resultados das imagens fração do produto MOD09 e produto MOD13A1 foram avaliados em relação à imagem ETM+ (dado de referência), por meio de uma análise de regressão. Finalmente, para testar a terceira hipótese, uma série de um ano de imagens índices de vegetação (NDVI e EVI) foi avaliada com o suporte de uma análise de variância, partindo-se do princípio que um evento de queimada diminui significativamente os valores destes índices.

\section{ÁREA DE ESTUDO}

A área de estudo localizou-se na porção norte do Estado do Mato Grosso, região Centro-oeste do Brasil. Esta foi definida pela cena $227 / 68$ do satélite Landsat $\left(10^{\circ} 37^{\prime}\right.$ e $12^{\circ} 30^{\prime}$ de latitude sul e $57^{\circ} 41^{\prime}$ e $55^{\circ} 29^{\prime}$ de longitude oeste) e cobriu uma área com cerca de $29.000 \mathrm{~km}^{2}$.

No extremo norte do Estado do Mato Grosso, a temperatura anual média é de cerca de $26^{\circ} \mathrm{C}$. Segundo Nimer (1977), a pluviosidade média anual atinge valores superiores a $2.700 \mathrm{~mm}$. Entretanto, a precipitação não se distribui igualmente ao longo do ano. Mais de $70 \%$ do total de chuvas se precipita entre novembro e março, sendo geralmente mais chuvoso o trimestre janeiro-março. Em contrapartida, em todo o Estado o inverno é excessivamente seco.

Além disso, nesta área vem ocorrendo uma alta taxa na conversão da cobertura vegetal não somente devido à recente utilização da agricultura mecanizada como também devido aos processos de desmatamento, corte seletivo e queimadas (INPE, 2005).

\section{As queimadas no Estado do Mato Grosso}

Neste Estado, a maior parte das queimadas ocorre durante a estação seca (maio à outubro) ou no início da estação úmida, sendo que para o ano de 2001, os meses que apresentaram um maior número de focos de incêndio foram junho, agosto, setembro e outubro (FEMA-MT, 2003).

O Mato Grosso pode ser considerado como um dos estados brasileiros mais importantes em relação ao número de focos de calor detectados. Para o ano de 1999, o percentual total de focos de calor foi de $39 \%$, em 2000 este percentual foi reduzido para 30\%, e em 2001 para 23\%. Segundo a FEMA-MT (Fundação Estadual do Meio Ambiente do Estado do Mato Grosso) esta diminuição e atribuída a maior eficiência do sistema SIDFOC (Sistema de Identificação de Focos de Calor) em relação ao antigo sistema utilizado SIDEQ (Sistema de Detecção de Queimadas), e também ao trabalho conjunto da própria FEMAMT, prefeituras, IBAMA (Instituto Brasileiro do Meio Ambiente e dos Recursos Naturais Renováveis), ONGs (Organizações nãogovernamentais) e trabalhos de educação ambiental nos entornos das áreas de conservação.

Com o período de estiagem, a vegetação se torna um meio de propagação de fogo, sendo o homem o maior responsável pelas queimadas. Todas as regiões do Mato Grosso se tornam áreas de alto risco para ocorrência de queimadas e incêndios florestais de grande proporção. Para o ano de 2001, verificouse que na Mesoregião Norte, os municípios de Sorriso, Ipiranga do Norte e Vera apresentaram 1.520, 1.250 e 1.016 focos de calor, respectivamente (FEMA, 2003), destacados pelos índices superiores a mil focos de calor.

$\mathrm{Na}$ Figura 2, observa-se a distribuição dos focos de calor por Mesoregióes no Estado do Mato Grosso no período de 1996 a 2002. Na Mesoregião Norte, observou-se um aumento no número de focos de incêndio, provavelmente relacionados à expansão do desmatamento nesta região.

\section{MATERIAIS E MÉTODOS}

\section{Base de dados de sensoriamento remoto}

\section{a) Sensor MODIS}

As cenas do sensor MODIS utilizadas para este estudo corresponderam ao tile H12V10. Duas imagens de reflectância diária referentes ao dia Juliano 278 ( 5 de outubro) do ano de 2002 foram analisadas. Uma disponibilizada no produto MOD09GQK e a outra no produto MOD09GHK. O produto MOD09GQK fornece as bandas $1 \mathrm{e} 2$ de reflectância espectrais da região do vermelho (V) e infravermelho próximo (IVP), com resolução espacial de 250 metros, centradas em $648 \mathrm{~nm}$ e 858 $\mathrm{nm}$, respectivamente. O produto MOD09GHK fornece sete bandas que variam da região do espectro visível ao infravermelho médio, com resolução espacial de $500 \mathrm{~m}$. No presente estudo, foram utilizadas as bandas três à sete, centradas em, $470 \mathrm{~nm}$, $555 \mathrm{~nm}, 1240 \mathrm{~nm}, 1640 \mathrm{~nm}$, e $2130 \mathrm{~nm}$, respectivamente (Justice et al., 2002). 


\section{ACTA AMAZONICA}

DETECÇÃO DE CICATRIZES DE ÁREAS QUEIMADAS BASEADA NO MODELO LINEAR DE MISTURA ESPECTRAL E IMAGENS ÍNDICE DE VEGETAÇÃO UTILIZANDO DADOS MULTITEMPORAIS DO SENSOR MODIS/TERRA NO ESTADO DO MATO GROSSO, AMAZÔNIA BRASILEIRA

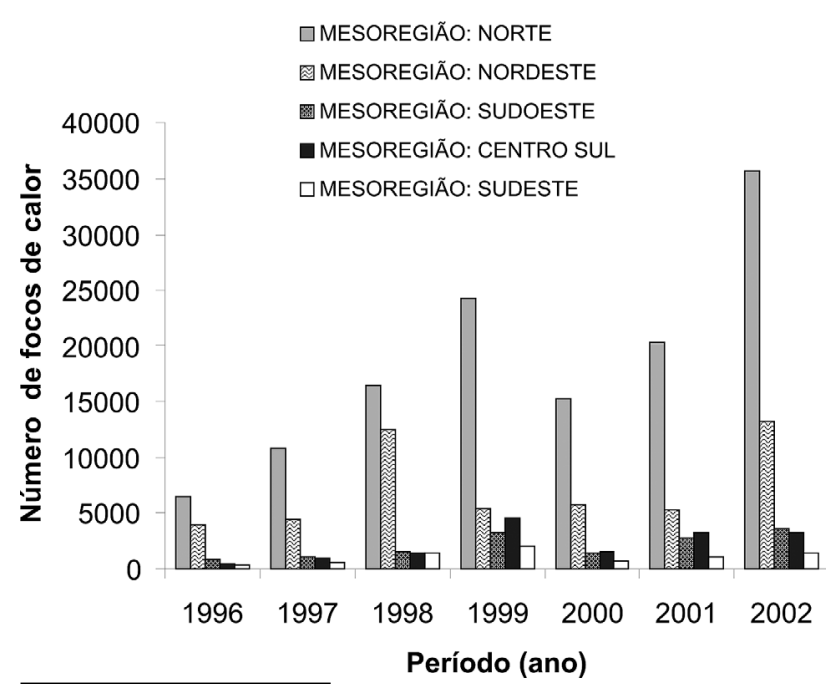

Figura 2 - Focos de calor nas Mesoregiões do Estado do Mato Grosso para o período 1996 a 2002. Fonte: Adaptado de FEMA/ COGEO/INPE (2003).

Foi utilizado também o produto MOD13A1, que é composto por um mosaico de 16 dias de imageamento. Neste produto sao disponibilizados os índices de vegetação NDVI e EVI, além dos mosaicos das bandas espectrais utilizadas para gerar estes índices. Estas bandas espectrais correspondem a região do azul (banda 3), vermelho (banda 1), infravermelho próximo (banda 2) e infravermelho médio (banda 7). As imagens dos meses de outubro e novembro de 2002 (uma para o mês de outubro e duas para novembro) contendo as bandas espectrais do produto MOD13A1 foram utilizadas. Além disso, 23 mosaicos de 16 dias das imagens índice de vegetação disponível no produto MOD13A1 para todo o ano de 2002 foram avaliados.

O NDVI é uma relação entre medidas espectrais (reflectância ( $\rho)$ de duas bandas, a do infravermelho próximo (IVP) (841$876 \mathrm{~nm}$ no sensor MODIS) e a do vermelho (V) (620-670 nm, no sensor MODIS), e visa eliminar diferenças sazonais do ângulo do Sol e minimizar os efeitos da atenuação atmosférica, observados para dados multitemporais (Huete et al., 1994; Huete et al., 1997). No caso do NDVI proveniente do produto MOD13A1, os dados já são corrigidos para os efeitos da atmosfera. Os valores obtidos com o NDVI são contidos em uma mesma escala de valores, entre -1 e 1 , utilizando-se a equação (equação 1):

$$
\text { NDVI }=(\rho I V P-\rho V) /(\rho I V P+\rho V)
$$

Onde: $\rho$ IVP é a reflectância da banda espectral do infravermelho próximo; $\mathrm{e} \rho$ Vé a reflectância da banda espectral do vermelho.

O índice de vegetação melhorado (EVI) foi desenvolvido para otimizar o sinal da vegetação, melhorando a sensibilidade em regiões com maior densidade de biomassa e reduzindo assim as influências atmosféricas. O EVI é calculado através da seguinte equação (equação 2):

$$
\mathrm{EVI}=\mathrm{G}(\rho \mathrm{IVP}-\rho \mathrm{V}) /(\mathrm{L}+\rho \mathrm{IVP}+\mathrm{C} 1 \text { vermelho-C2 azul })
$$

Onde: $\mathrm{L}=$ fator de ajuste para os componentes abaixo do dossel (canopy background);

C1 e C2 = coeficientes para ajuste das resistências dos efeitos dos aerossóis da atmosfera; $\mathrm{G}$ = fator de ganho; IVP é a reflectância da banda espectral do infravermelho próximo; $\mathrm{e} \rho \mathrm{V}$ é a reflectância da banda espectral do vermelho.

Os coeficientes adotados pelo algoritmo do EVI são: $\mathrm{L}=1$, $\mathrm{C} 1=6, \mathrm{C} 2=7,5$ e G = 2,5 (Huete et al., 1994; Huete et al., 1997).

\section{b) Sensor ETM+}

Foi selecionada uma imagem da órbita/ponto: $227 / 68$ referente ao dia Juliano 278 ( 05 de outubro) do ano de 2002, coincidente com a data da imagem MODIS do produto MOD09. Esta cena foi utilizada como dado de referência para a avaliação quantitativa da potencialidade do sensor MODIS na detecção de áreas recém queimadas, devido a sua melhor resolução espacial.

\section{Processamentos}

Pré-processamento para as cenas MODIS e ETM+.

\section{a) Cenas MODIS}

Os dados MODIS foram adquiridos no formato HDF. Estes dados foram convertidos para o formato Geotiffe reprojetados para projeção Geográfica com o auxílio do aplicativo MODIS Reprojection Tool (MRT). Utilizando este mesmo aplicativo, as bandas espectrais do produto MOD09GHK foram reamostradas de $500 \mathrm{~m}$ para $250 \mathrm{~m}$ de resolução espacial, através de uma duplicação simples da matriz (vizinho mais próximo). Desta forma, toda a base de dados do sensor MODIS foi padronizada com a mesma resolução espacial antes das demais etapas de processamento.

As imagens MODIS foram convertidas de 16 para 8 bits para que os dados fossem processados no aplicativo SPRING. Este processamento pode levar a perda de informações caso sejam utilizados os programas convencionais, que tendem a normalizar os dados utilizando o menor e o maior valor possível armazenado em um inteiro de 16 bits (sinal variando de - 32.768 $a+32.768$ ), dificultando a padronização desta conversão para diferentes imagens/datas. Para evitar esta perda de informação, foi desenvolvido um aplicativo de livre circulação na DSR/INPE (Divisão de Sensoriamento Remoto/ Instituto Nacional de Pesquisas Espaciais) que recupera os valores reais de cada pixel dos dados MODIS, e converte a reflectância para números digitais (ND), permitindo o controle desta transformação (Arai, 2002, comunicação pessoal).

Para a série temporal das imagens do produto MOD13A1 optou-se pela geração de mosaicos mensais de forma a reduzir o espaço de armazenamento de cada cena (500 MB para cada mosaico) e também o tempo de processamento. 


\section{ACTA AMAZONICA}

DETECÇÃO DE CICATRIZES DE ÁREAS QUEIMADAS BASEADA NO MODELO LINEAR DE MISTURA ESPECTRAL E IMAGENS ÍNDICE DE VEGETAÇÃO UTILIZANDO DADOS MULTITEMPORAIS DO SENSOR MODIS/TERRA NO ESTADO DO MATO GROSSO, AMAZÔNIA BRASILEIRA
A geração destes mosaicos foi realizada através de linhas de comando em linguagem $\mathrm{C}++$, de forma que os pixels da imagem resultante foram selecionados com base no valor mais alto do NDVI entre as datas, objetivando-se a eliminação de nuvens. Assim, os pixels que na imagem NDVI apresentaram valor mais alto entre dois mosaicos de 16 dias, foram selecionados para a composição da imagem mensal, e os mesmos pixels da imagem EVI e bandas espectrais foram também selecionados, reduzindo-se desta forma de 23 para 12 mosaicos.

\section{b) Cenas ETM+}

Após a importação destas imagens para o banco de dados, foi realizada a etapa de georreferenciamento desta imagem. $\mathrm{O}$ registro foi baseado em uma cena do projeto PRODES (Projeto de Estimativa do Desflorestamento da Amazônia) [disponível online]. Devido a cena do projeto PRODES apresentar-se bem ajustada quando sobreposta a base de dados do IBGE (limites de município e estradas) e às imagens MODIS, sendo ambos já disponibilizados georeferenciados. O erro médio de registro entre as cenas ETM+ foi menor que 0,5 pixel.

Geração e aplicação do modelo linear de mistura espectral na série temporal de imagens ETM+, MOD09 e MOD13A1.

Neste modelo, uma relação linear é utilizada para representar a mistura espectral dos alvos em cada pixel. Assim, a resposta espectral dos pixels em qualquer comprimento de onda pode ser considerada como uma combinação de cada componente da mistura. Neste estudo, utilizou-se um modelo que estima a proporção de cada uma das componentes desejadas, minimizando a soma dos quadrados dos erros (Minímos Quadrados Ponderado). Para isso, o número de componentes deve ser menor que o número de bandas espectrais utilizadas, a proporção das componentes deve ser não negativa, e sua somatória deve ser igual a 1 (Shimabukuro e Smith, 1991). Os valores de proporção das imagens sintéticas geradas por este modelo apresentam-se no intervalo zero a um, isto é, com significado físico, e são automaticamente escalonados para o intervalo de 100 a 200 , de forma que o valor 100 em ND representa uma proporção zero enquanto que o valor 200 representa $100 \%$ da fração estudada.

Os pixels puros ou endmembers utilizados como dado de entrada para os modelos foram selecionados diretamente na imagem, através da seleção de pixels com a resposta espectral mais próxima da curva teórica esperada para alvos puros (Figura 3). Os modelos foram gerados independentemente para cada uma das imagens, e partiu-se da hipótese que é possível encontrar um pixel puro nas imagens MODIS, dada as características e diversidade da área estudada. Os endmembers para cada um dos conjuntos de dados foram: vegetação selecionado em áreas de cultura agrícola; solo - selecionado em áreas de solo exposto; sombra - selecionado em áreas de corpos d'água sem sedimentos.

O modelo linear de mistura espectral pode ser escrito como:

$$
r_{i}=a * \operatorname{veg}_{i}+b * \operatorname{solo}_{i}+c * \operatorname{sombra}_{i}+e_{i}
$$

Onde $r_{i}$ é a resposta da reflectância do pixel na banda i; a, b e c são as proporções de vegetação, solo e sombra, respectivamente; veg, solo e sombra são as respostas espectrais das componentes vegetação, solo e sombra (ou água), respectivamente; $e_{i}$ é o erro na banda ${ }_{i} e_{i}$ indica a banda a ser utilizada.

Para avaliar a consistência do modelo aplicado às imagens ETM+, MOD09 e MOD13A1, analisou-se o número e a (a) ETM+

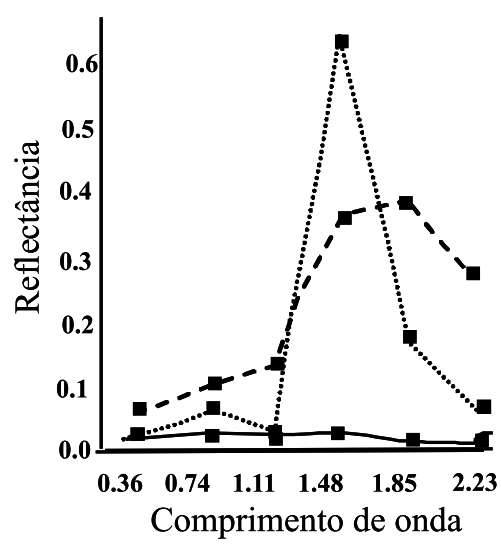

(b) MOD09

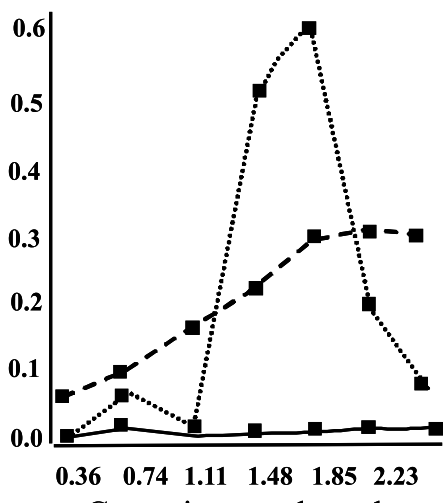

Comprimento de onda (c) MOD13A1

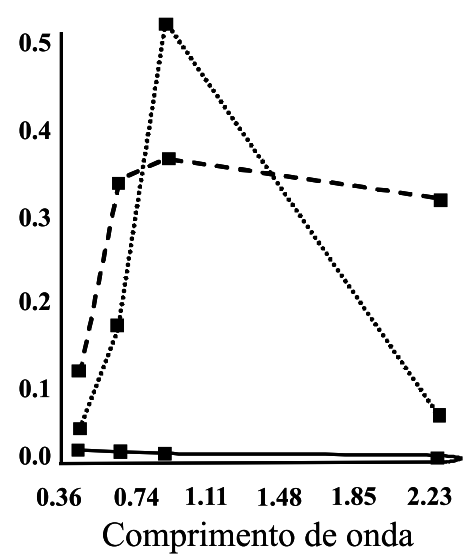

Sombra

Solo

Figura 3 - Resposta espectral dos endmembers utilizados como dado de entrada para os modelos. (a) Imagem ETM+; (b) Produto MOD09; (c) Produto MOD13A1, mês de outubro. 
proporção dos valores dos pixels menores do que $100 \mathrm{e}$ maiores que 200 nas imagens fração utilizadas. Os valores fora desse intervalo foram considerados incoerentes.

\section{Delineamento Amostral e Análise dos Dados}

O delineamento amostral baseou-se na definição de 126 polígonos na cena ETM+ correspondente ao dia Juliano 278 do ano de 2002. Estes polígonos foram delimitados a partir da edição manual somente dentro de áreas que haviam sido desmatadas após outubro de 2001, baseado nos dados do projeto PRODES digital para o ano de 2001 e 2002. No processo de edição destas amostras, tomou-se o cuidado de não utilizar as bordas das áreas recém queimadas. Este procedimento foi adotado para minimizar os efeitos de mistura da resposta espectral das cicatrizes de áreas queimadas com os alvos do entorno já que esses mesmos polígonos foram utilizados para a avaliação das imagens MODIS, que possuem uma menor resolução espacial.

Com base nas áreas amostradas, foram extraídos os valores referentes a média e desvio padrão dos níveis digitais (ND) das imagens fração sombra, solo e vegetação e dos índices de vegetação. Este procedimento foi aplicado para as imagens ETM+, produto MOD09, e produto MOD13A1.

A resposta espectral das áreas queimadas nas imagens fração (solo, sombra e vegetação) derivadas do sensor ETM+ e MODIS foram avaliadas com base na distribuição de freqüência dos níveis digitais das amostras.

Para validar os resultados da detecção das cicatrizes de áreas queimadas com os dados do sensor MODIS, foi realizada uma análise de regressão onde os valores da proporção da fração sombra nas imagens MODIS (MOD09 e MOD13A1) foram relacionados com os valores da proporção de sombra na imagem ETM+ (dado de referencia).

Finalmente, para verificar se os índices de vegetação (NDVI e EVI) são sensíveis às mudanças na cobertura da terra devido aos eventos de queimada, os valores médios mensais das amostras foram comparados por meio de um teste de Tukey. Este teste baseou-se na hipótese de que a ocorrência de uma queimada reduz significativamente os valores médios mensais dos índices de vegetação. Portanto, as datas consecutivas à ocorrência de queimadas devem apresentar valores de NDVI e EVI significativamente mais baixos que as demais datas.

\section{RESULTADOS E DISCUSSÃO}

\section{Análise do modelo de mistura espectral}

A análise da consistência do modelo de mistura espectral mostrou que para um total de 140.193 .459 pixels das imagens fração ETM +, 1.853 .870 pixels (1\% do total) apresentaram valores incoerentes. Esta análise foi repetida para os dados MOD09 e MOD13A1, para os meses de outubro e novembro.
Para todas as imagens MODIS, o número total de pixels avaliados foi 2.628.744, sendo que para o produto MOD09, foram encontrados 95.234 pixels com valores incoerentes ( $4 \%$ do total). Para o produto MOD13A1 referente ao mês de outubro, este número foi de $135.424 \mathrm{e}$ para o mês de novembro, foi de 151.729 pixels com valores incoerentes correspondendo a $5 \%$ e $6 \%$ do total de pixels, respectivamente (Tabela 1).

Observa-se na Tabela 1, que a imagem fração solo foi a que apresentou uma maior porcentagem de pixels com valores incoerentes em todo o conjunto de dados. Este resultado pode ser atribuído a resposta espectral de alvos que não foram incluídos no modelo, como por exemplo, centros urbanos. Os erros associados às imagen fração sombra não ultrapassaam $1 \%$, enquanto que nas imagens fração vegetação, obteve-se um erro de até $8 \%$ (produto MOD09).

\section{O uso da fração sombra para a detecção de áreas recém queimadas}

Os polígonos amostrais na imagem ETM + apresentaram, como o esperado, uma proporção de sombra mais alta que a proporção de solo, refletindo a resposta espectral de cicatrizes recentes de áreas queimadas (Figura 4). Este fato e atribuído a baixa reflectância dos alvos queimados em todas as bandas espectrais (Shimabukuro e Smith, 1991; Pereira e Setzer, 1993). Como as amostras foram adquiridas em áreas com cicatrizes de queimadas recentes, a proporção de vegetação apresentou valores entorno $0 \%$ na imagem ETM+.

A análise dos histogramas gerados para as imagens sintéticas derivadas do modelo linear de mistura espectral do sensor ETM + mostrou que não existe sobreposição dos histogramas, evidenciando a nítida separação dos valores de ND nas diferentes imagens fração. A imagem sintética fração solo (Figura 4a) apresentou um valor mínimo de 120 e máximo de 148; já na imagem fração sombra (Figura 4b) os valores variaram entre 160 e 187, e na imagem fração vegetação (Figura 4c) esse intervalo foi entre 96 e 101.

Pereira e Setzer (1993) analisaram as cicatrizes de áreas queimadas em imagens TM, e demonstraram que a banda 4 $(760-900 \mathrm{~nm})$ apresentou a maior capacidade de separar as áreas queimadas dos demais alvos da cena. O histograma

Tabela 1 - Porcentagem dos pixels com valores incoerentes para as imagens fração derivadas do modelo linear de mistura espectral.

\begin{tabular}{llll}
\hline \hline & \multicolumn{3}{l}{$\begin{array}{l}\text { \% do toal de pixels com valores } \\
\text { incoerentes }\end{array}$} \\
\cline { 2 - 4 } Dados & Fração solo & $\begin{array}{l}\text { Fração } \\
\text { sombra }\end{array}$ & $\begin{array}{l}\text { Fração } \\
\text { vegetação }\end{array}$ \\
\hline ETM+ & $3 \%$ & $0,2 \%$ & $1 \%$ \\
MOD09 & $3 \%$ & $0,2 \%$ & $8 \%$ \\
MOD13A1 Out. & $14 \%$ & $0,0 \%$ & $0,3 \%$ \\
MOD13A1 Nov. & $12 \%$ & $1 \%$ & $5 \%$ \\
\hline \hline
\end{tabular}




\section{ACTA \\ AMAZONICA}

DETECÇÃO DE CICATRIZES DE ÁREAS QUEIMADAS BASEADA NO MODELO LINEAR DE MISTURA ESPECTRAL E IMAGENS ÍNDICE DE VEGETAÇÃO UTILIZANDO DADOS MULTITEMPORAIS DO SENSOR MODIS/TERRA NO ESTADO DO MATO GROSSO, AMAZÔNIA BRASILEIRA apresentado por esses autores aponta para uma sobreposição entre os valores das áreas queimadas e florestas intactas no final da curva do histograma. As cicatrizes das áreas queimadas apresentaram valores mínimo e máximo de 12 e 61 ND, respectivamente, enquanto que nas áreas de floresta, os valores variaram numa faixa de 52 e 99 ND. Portanto, os resultados encontrados no presente estudo demonstraram que para a imagem ETM + a técnica do modelo linear de mistura espectral possibilita a distinção da resposta espectral de cicatrizes de áreas queimadas, realçando esta característica na imagem sintética fração sombra.

Quando comparamos os dados MOD09, do dia 278, com os dados ETM+, verificou-se que a proporção de sombra na imagem ETM + apresenta um valor médio maior (73\%) que na imagem fração sombra MOD09 (58\%). Além disso, devido à resolução espacial do sensor MODIS, observou-se também a presença de vegetação nos polígonos amostrados, indicando uma mistura de alvos nos pixels (Figura 5). Através das análises dos histogramas das imagens fração, para a imagem do produto MOD09, observou-se que a imagem sintética fração solo apresenta valores em ND variando de 111 a 166, a imagem sintética fração sombra apresenta valores entre 140 e 171 e a imagem sintética fração vegetação varia entre 96 e 127 (Figura 5a, 5b e 5c, respectivamente). Portanto foi observado que para o produto MOD09 houve uma sobreposição entre os valores das imagens fração sombra e solo, mas não entre as imagens fração sombra e vegetação dentro das áreas amostradas. No entanto, para a imagem sintética fração solo, constatou-se que o valor encontrado com maior freqüência foi $141 \mathrm{ND}$, enquanto que para a fração sombra, este valor foi mais alto: 157 e 159 ND.

A análise dos dados do produto MOD13A1 (composições mensais de outubro e novembro) mostrou que apesar deste produto apresentar a mesma resolução espacial que o produto MOD09, nota-se para ambos os meses, uma maior proporção de vegetação nas amostras (Figura 6c e 6f, respectivamente). Isto se deve à composição ser realizada com base nos máximos valores de NDVI (Huete et al., 1999). Assim, quando ocorre algum evento que diminui o valor do índice de vegetação nas imagens (como as queimadas) dentro de um intervalo de 16 dias, é utilizado para a composição final do mosaico os pixels que apresentam os valores mais altos de NDVI, mascarando a ocorrência do evento. Desta forma, é inserido dentro dos polígonos amostrais pixels com maiores proporções de vegetação, diminuindo o valor médio das imagens fração sombra: $56 \%$ para as amostras adquiridas no mês de outubro, e de $54 \%$ no mês de novembro, valores inferiores aos encontrados com as imagens diárias.

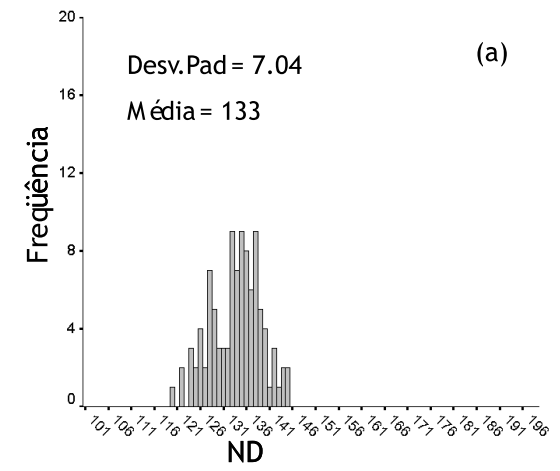

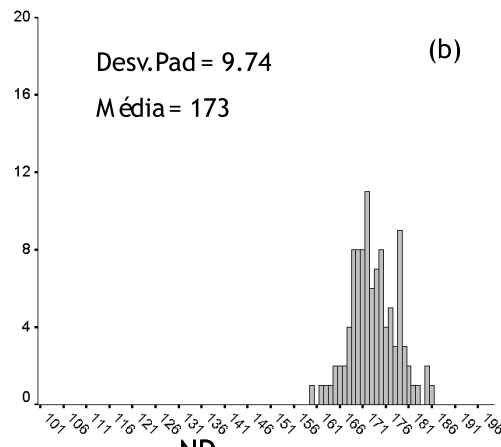

ND

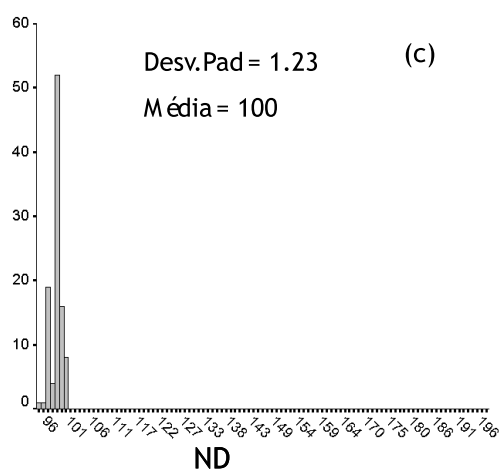

Figura 4 - Histograma de distribuição de freqüência dos valores em Número Digital para os dados ETM+: (a) fração solo; (b) fração sombra; e (c) fração vegetação.

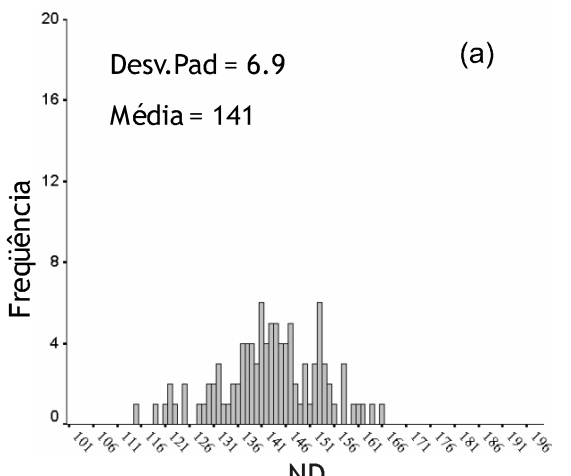

ND

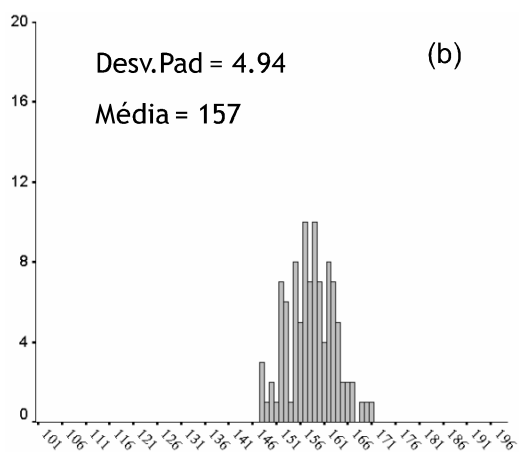

ND

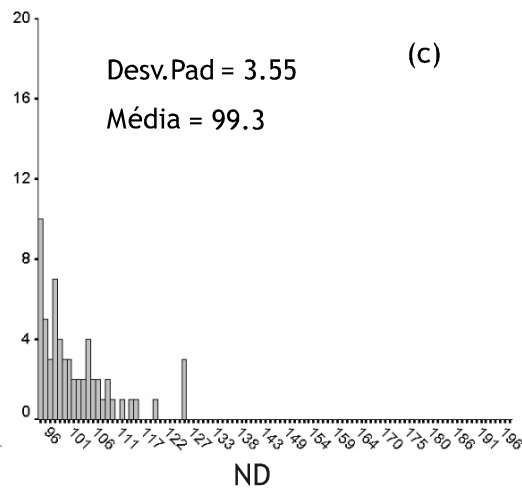

ND

Figura 5 - Histograma de freqüência de distribuição dos valores em Número Digital para os dados MOD09: (a) fração solo; (b) fração sombra; e (c) fração vegetação. 


\section{ACTA AMAZONICA}

DETECÇÃO DE CICATRIZES DE ÁREAS QUEIMADAS BASEADA NO MODELO LINEAR DE MISTURA ESPECTRAL E IMAGENS ÍNDICE DE VEGETAÇÃO UTILIZANDO DADOS MULTITEMPORAIS DO SENSOR MODIS/TERRA NO ESTADO DO MATO GROSSO, AMAZÔNIA BRASILEIRA
Em relação à análise dos histogramas das imagens fração sombra para os mosaicos mensais do produto MOD13A1, observou-se que a amplitude de variação dos valores em ND abrange um intervalo maior de valores que os encontrados para o produto MOD09 e ETM+. Para o mês de outubro, a variação foi de 126 a 175, enquanto que para o mês de novembro, esta variação foi de 116 a 181 (Figura 6a e 6d, respectivamente). Este resultado indica uma maior limitação deste produto para caracterização espectral das áreas recém queimadas utilizando imagem fração sombra, em relação ao produto MOD09 e aos dados ETM.

Os resultados da regressão entre os dados das imagens fração sombra do produto MOD09 e ETM+ destacaram dois fatos interessantes em relação aos dados MODIS. Os polígonos que contém apenas 1 pixel do sensor MODIS geram um aumento do resíduo da regressão, provavelmente devido aos efeitos da mistura de alvos (Figura 7a). Este fato é reforçado pela análise prévia das imagens fração, que confirma a ocorrência da fração vegetação nas cicatrizes das áreas queimadas. Por outro lado, quando esses polígonos são desconsiderados da análise (Figura 7b), o que reduz o número amostral de 126 para 101, o coeficiente de determinação $\left(\mathrm{R}^{2}\right)$ entre os dados ETM+ e MODIS aumenta de 0,29 para 0,67 ( $\mathrm{p}<0,01)$.

Este resultado indica que é possível utilizar as imagens fração sombra derivadas do produto MOD09 para detectar cicatrizes de áreas recém queimadas maiores que um pixel. No entanto, a análise de regressão mostrou que as imagens fração sombra derivadas das composições mensais dos meses de outubro e novembro do produto MOD13A1 não apresentaram relação com os dados ETM+. Para as áreas recém queimadas maiores que 1 pixel do sensor MODIS, foi encontrado um $\mathrm{R}^{2}=$ 0,09 para o mês de outubro $R^{2}=0,07$ para o mês de novembro, refletindo a maior sobreposição entre os histogramas das imagens fração do produto MOD13 em relação ao MOD09 e ETM+.

A análise dos dados MODIS, que possuem uma resolução espacial mais baixa que o sensor ETM+, mostrou como principal limitação a ocorrência de uma mistura de alvos nos polígonos amostrados. Esta mistura de alvos pode também estar relacionada com os efeitos de geolocalização inerentes a sensores de média e baixa resolução espacial (Razafimpanilo et al., 1995).

\section{O uso de imagens índice de vegetação para a detecção de eventos de queimadas}

Em relação a utilização de imagens índice de vegetação para o monitoramento de queimadas, foi realizado o teste de
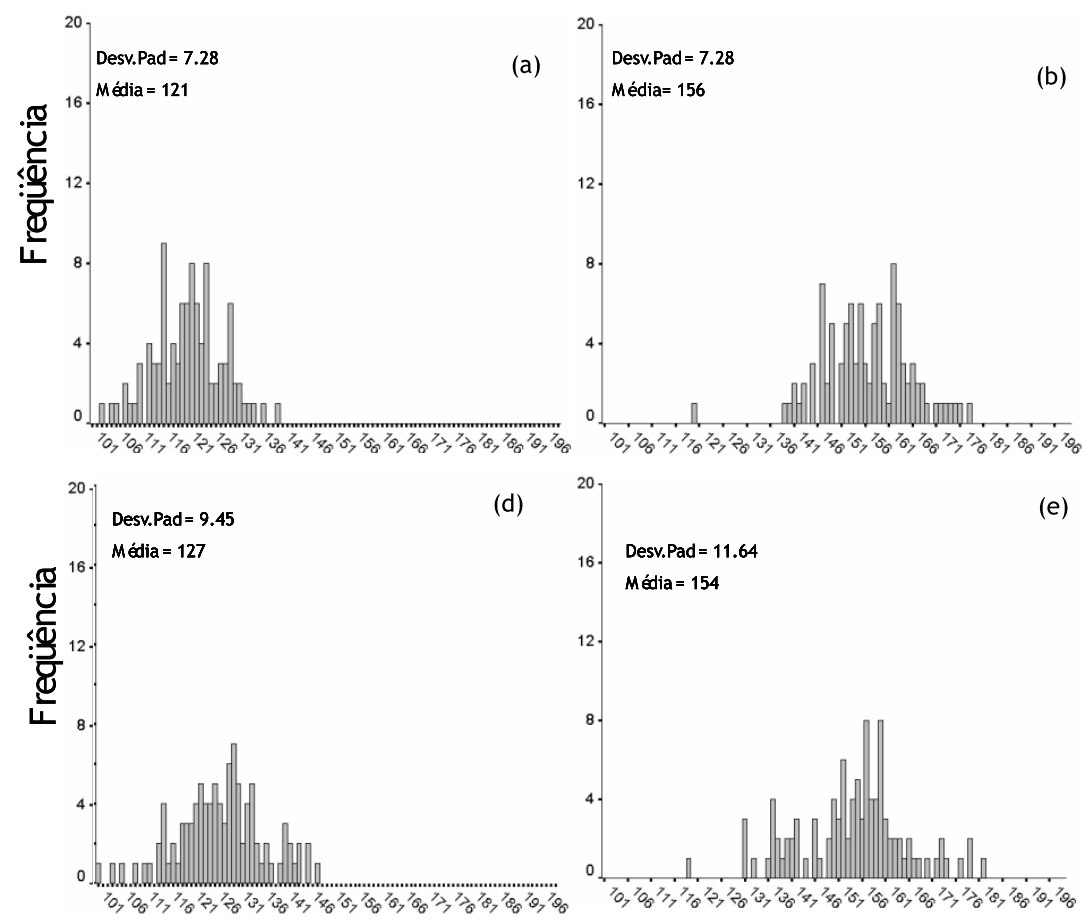

ND

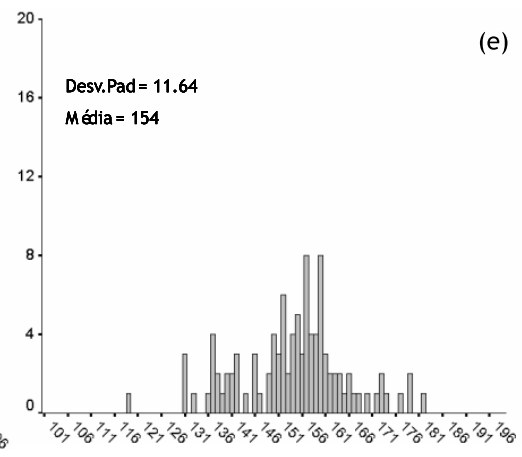

ND

(e)
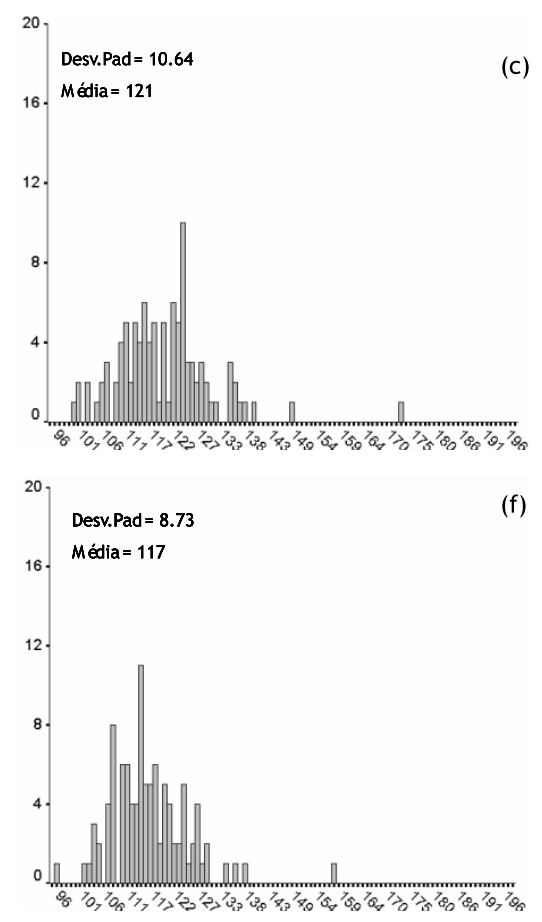

ND

Figura 6 - Histograma de freqüência de distribuição dos valores em Número Digital para os dados MOD13A1 para o mês de outubro: (a) fração solo; (b) fração sombra; e (c) fração vegetação; e mês de novembro: (d) fração solo; (e) fração sombra; e (f) fração vegetação. 


\section{ACTA \\ AMAZONICA}

DETECÇÃO DE CICATRIZES DE ÁREAS QUEIMADAS BASEADA NO MODELO LINEAR DE MISTURA ESPECTRAL E IMAGENS ÍNDICE DE VEGETAÇÃO UTILIZANDO DADOS MULTITEMPORAIS DO SENSOR MODIS/TERRA NO ESTADO DO MATO GROSSO, AMAZÔNIA BRASILEIRA
Tukey, considerando uma provabilidade de $5 \%$ para a significância. Observou-se que para os dados de NDVI e EVI, existem diferenças significativas entre quase todos os pares de meses (Tabela 2). Este resultado mostrou a dificuldade em estabelecer um padrão de resposta espectral para as cicatrizes de áreas recém queimadas a partir da análise intra-anual dos valores médios dos índices de vegetação. Isso se deve provavelmente ao efeito de mudanças sazonais da vegetação ao longo do ano, dentro dos polígonos amostrados, impossibilitando a identificação do período em que ocorreu o evento de queima. Os polígonos amostrados foram selecionados em áreas desmatadas durante o ano de 2001.
Nestas áreas geralmente encontram-se gramíneas, que respondem rapidamente à precipitação na estação chuvosa, assim como à seca durante a estiagem das chuvas. Este intenso padrão sazonal dificulta a separação entre mudanças devido a causas antrópicas (queimadas) e mudancas fenológicas da cobertura vegetal.

Na Figura 8, é apresentada a variação dos valores médios do NDVI e EVI ao longo do ano de 2002, para a análise da detecção de cicatrizes de áreas recém queimadas em uma série multitemporal. Observou-se que no mês de janeiro, o NDVI apresentou o valor médio mais baixo $(0,87)$ que nos demais meses referentes à estação chuvosa, enquanto que o EVI

Tabela 2 - Resultado do teste de Tukey para as amostras de NDVI e EVI. Apresentam-se os valores da probabilidade $(p)$. Observamse também a média mensal e os valores de desvio padrão das amostras $(n=101)$.

\begin{tabular}{|c|c|c|c|c|c|c|c|c|c|c|c|c|}
\hline NDVI & Jan & Fev & Mar & Abr & Maio & Jun & Jul & Ago & Set & Out & Nov & Dez \\
\hline média & 0,940 & 0,902 & 0,896 & 0,865 & 0,852 & 0,841 & 0,758 & 0,764 & 0,826 & 0,791 & 0,803 & 0,780 \\
\hline DP & 0,053 & 0,057 & 0,056 & 0,074 & 0,067 & 0,067 & 0,104 & 0,092 & 0,050 & 0,057 & 0,063 & 0,065 \\
\hline Jan & & 0,008 & 0,000 & 0,000 & 0,000 & 0,000 & 0,000 & 0,000 & 0,000 & 0,000 & 0,000 & 0,000 \\
\hline Fev & & & 0,999 & 0,008 & 0,000 & 0,000 & 0,000 & 0,000 & 0,000 & 0,000 & 0,000 & 0,000 \\
\hline Mar & & & & 0,074 & 0,000 & 0,000 & 0,000 & 0,000 & 0,000 & 0,000 & 0,000 & 0,000 \\
\hline Abr & & & & & 0,973 & 0,364 & 0,000 & 0,000 & 0,003 & 0,000 & 0,000 & 0,000 \\
\hline Maio & & & & & & 0,993 & 0,000 & 0,000 & 0,234 & 0,000 & 0,000 & 0,000 \\
\hline Jun & & & & & & & 0,000 & 0,000 & 0,922 & 0,000 & 0,005 & 0,000 \\
\hline Jul & & & & & & & & 0,999 & 0,000 & 0,038 & 0,000 & 0,516 \\
\hline Ago & & & & & & & & & 0,000 & 0,225 & 0,005 & 0,910 \\
\hline Set & & & & & & & & & & 0,021 & 0,456 & 0,000 \\
\hline Out & & & & & & & & & & & 0,989 & 0,994 \\
\hline Nov & & & & & & & & & & & & 0,475 \\
\hline \multicolumn{13}{|l|}{ Dez } \\
\hline EVI & Jan & Fev & Mar & Abr & Maio & Jun & Jul & Ago & Set & Out & Nov & Dez \\
\hline média & 0,750 & 0,725 & 0,738 & 0,701 & 0,700 & 0,690 & 0,632 & 0,656 & 0,692 & 0,639 & 0,640 & 0,656 \\
\hline DP & 0,052 & 0,045 & 0,053 & 0,057 & 0,050 & 0,046 & 0,075 & 0,082 & 0,062 & 0,046 & 0,046 & 0,048 \\
\hline Jan & & 0,083 & 0,939 & 0,000 & 0,000 & 0,000 & 0,000 & 0,000 & 0,000 & 0,000 & 0,000 & 0,000 \\
\hline Fev & & & 0,913 & 0,124 & 0,098 & 0,000 & 0,000 & 0,000 & 0,003 & 0,000 & 0,000 & 0,000 \\
\hline Mar & & & & 0,000 & 0,000 & 0,000 & 0,000 & 0,000 & 0,000 & 0,000 & 0,000 & 0,000 \\
\hline Abr & & & & & 1 & 0,963 & 0,000 & 0,000 & 0,996 & 0,000 & 0,000 & 0,000 \\
\hline Maio & & & & & & 0,977 & 0,000 & 0,000 & 0,998 & 0,000 & 0,000 & 0,000 \\
\hline Jun & & & & & & & 0,000 & 0,001 & 0,999 & 0,000 & 0,000 & 0,001 \\
\hline Jul & & & & & & & & 0,132 & 0,000 & 0,999 & 0,998 & 0,123 \\
\hline Ago & & & & & & & & & 0,000 & 0,647 & 0,687 & 1 \\
\hline Set & & & & & & & & & & 0,000 & 0,000 & 0,000 \\
\hline Out & & & & & & & & & & & 1 & 0,629 \\
\hline Nov & & & & & & & & & & & & 0,669 \\
\hline Dez & & & & & & & & & & & & \\
\hline
\end{tabular}




\section{ACTA AMAZONICA}

DETECÇÃO DE CICATRIZES DE ÁREAS QUEIMADAS BASEADA NO MODELO LINEAR DE MISTURA ESPECTRAL E IMAGENS ÍNDICE DE VEGETAÇÃO UTILIZANDO DADOS MULTITEMPORAIS DO SENSOR MODIS/TERRA NO ESTADO DO MATO GROSSO, AMAZÔNIA BRASILEIRA
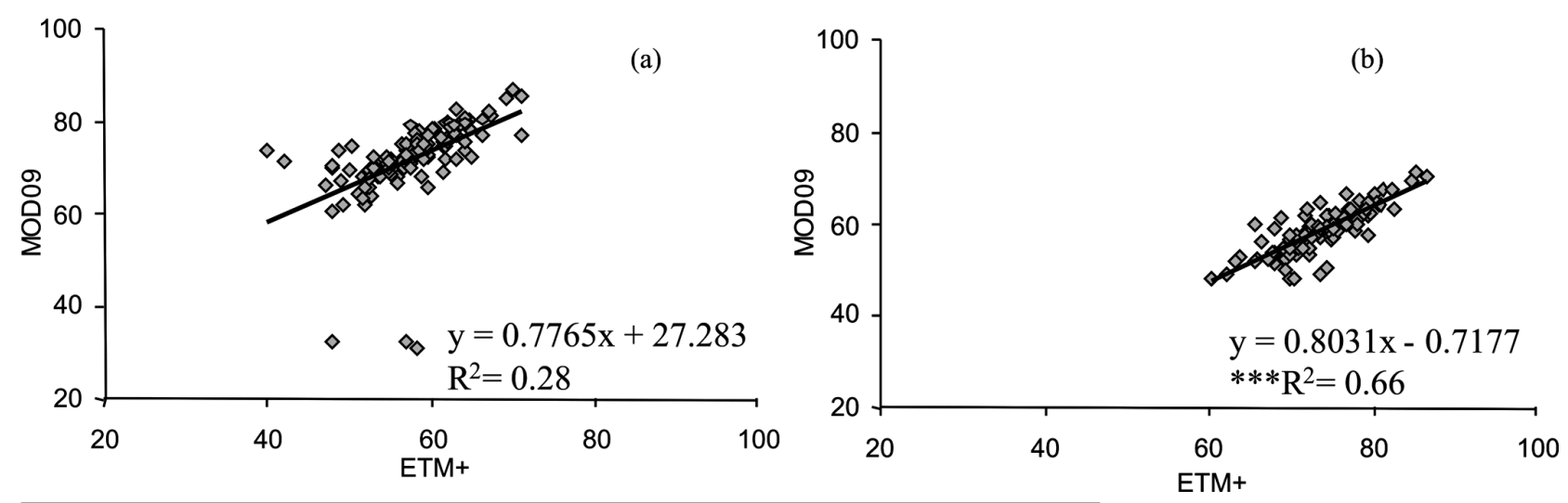

Figura 7 - Gráfico de dispersão dos polígonos amostrados nas imagens fração sombra dos dados ETM+ em relação aos dados do produto MOD09. Em (a) apresenta-se todas as amostras coletadas $(n=126)$; (b) amostras coletadas com área maior que 1 pixel do sensor MODIS $(\mathrm{n}=101)$. ${ }^{* * *}$ indica $\mathrm{p}<0,01$.

apresentou o valor médio mais alto em janeiro $(0,78)$ que nos demais meses.

A queda no valor médio de NDVI e alta no valor médio de EVI para o mês de janeiro pode ser explicado pela alta presença de nuvens nesta época do ano. A presença de nuvens na região faz com que ocorra um maior espalhamento da radiação, afetando a reflectância dos comprimentos de ondas menores (no caso destes índices de vegetação, o azul e o vermelho) (Diner, 1985). O NDVI, que é afetado mais pela resposta da banda do vermelho que a do infravermelho próximo, apresentou um valor maior no divisor que no dividendo da equação, resultando em um valor médio mais baixo. Já o EVI para este mesmo mês, apresentou um valor mais alto, devido aos coeficientes de correção atmosférica das bandas do vermelho e do azul, presentes na fórmula. A pequena oscilação dos valores de NDVI para os meses de fevereiro a junho, e a queda constante nos valores de EVI para o mesmo período pode ser explicada pela saturação do NDVI e maior sensibilidade do EVI, às mudanças sazonais ou da cobertura da terra ao longo destes meses.

O mês de julho foi o que apresentou os valores médios mais baixos para ambos os índices, devido a resposta espectral das gramíneas encontradas em áreas desmatadas, em condição de estresse hídrico devido a estação seca. No mês de setembro nota-se um pequeno aumento nos valores dos dois índices, que pode ser devido a uma rebrota ou crescimento de gramíneas nestas áreas. No mês de outubro, ocorre uma nova queda nos valores dos índices, pois todas as amostras estavam localizadas em áreas recém queimadas, delimitadas na imagem ETM+, do dia 5 de outubro. Para o mês de dezembro, observamse valores baixos dos dois índices. Neste caso, assim como no mês de janeiro, este resultado deve-se a presença de nuvens, e o comportamento se repete com o NDVI apresentando um valor mais baixo e o EVI um valor mais alto que no mês de julho.

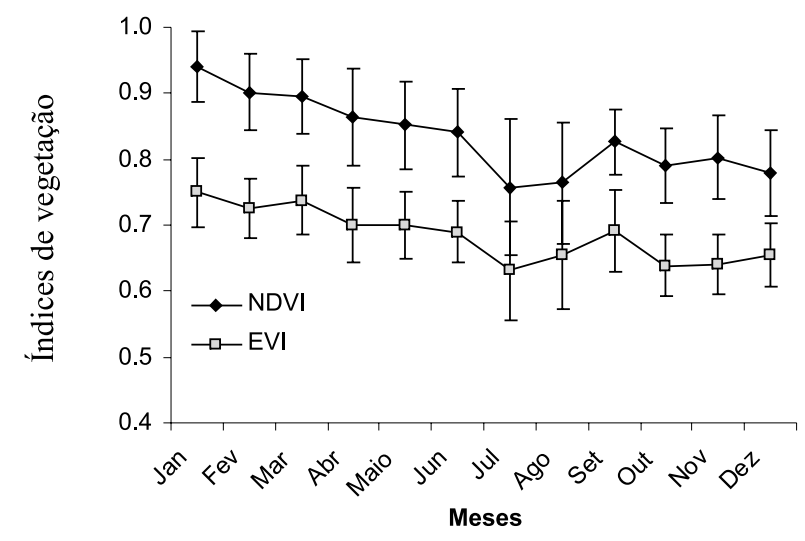

Figura 8 - Evolução mensal da média dos valores dos índices NDVI e EVI do produto MOD13A1 nos polígonos amostrados em 5 de outubro de 2002, com base na imagem ETM+. As barras verticais representam o valor de 1 desvio padrão.

\section{CONCLUSÕES}

A estratégia metodológica utilizada neste estudo, a partir da edição manual de polígonos na cena ETM+, mostrou-se eficaz para quantificar a eficiência dos produtos MODIS na detecção de áreas queimadas.

A imagem fração sombra gerada a partir da aplicação do modelo linear de mistura espectral na imagem diária do sensor MODIS (produto MOD09), apresentou um maior potencial para a identificação de cicatrizes de áreas queimadas que as imagens fração sombra de mesma resolução espacial, derivadas das composições mensais do produto MOD13A1. A fração sombra extraída do produto MOD09 apresentou uma concordância satisfatoria, explicando $67 \%$ da variação encontrada no dado do sensor ETM+. 


\section{ACTA \\ AMAZONICA}

DETECÇÃO DE CICATRIZES DE ÁREAS QUEIMADAS BASEADA NO MODELO LINEAR DE MISTURA ESPECTRAL E IMAGENS ÍNDICE DE VEGETAÇÃO UTILIZANDO DADOS MULTITEMPORAIS DO SENSOR MODIS/TERRA NO ESTADO DO MATO GROSSO, AMAZÔNIA BRASILEIRA
Este estudo demonstrou também que áreas queimadas iguais ou menores que um pixel do sensor MODIS são afetadas pela mistura de alvos, comprometendo a resposta espectral recebida pelo sensor e reduzindo a qualidade da detecção desses eventos.

O resultado do monitoramento de cicatrizes de áreas queimadas com base nos índices NDVI e EVI mostrou a dificuldade em estabelecer um padrão de resposta espectral das cicatrizes de áreas recém queimadas devido a interferência da resposta sazonal da vegetação presente nas áreas préviamente desmatadas.

\section{AGRADECIMENTOS}

À Fundação de Aperfeiçoamento de Pessoal de Nível Superior (CAPES), pela concessão da bolsa de mestrado do primeiro autor. À Fundação de Amparo á Pesquisa do Estado de São Paulo (FAPESP) pelo financiamento do projeto (Proc. 2003/01727-0). Aos revisores, que contribuíram significativamente para a melhora do manuscrito.

\section{BIBLIOGRAFIA CITADA}

Almeida-Filho, R; Shimabukuro , Y.E. 2002. Digital processing of a Landsat-TM time series for mapping and monitoring degraded areas caused by independent gold miners, Roraima State, Brazilian Amazon. Remote Sensing of Environment, 79: 42-50.

Anderson, L.O.; Shimabukuro, Y.E; DeFries, R.S.; Morton, D. 2005. Assessment of deforestation in near real time over the brazilian amazon using multitemporal fraction images derived from Terra/MODIS. IEEE Geoscience and Remote Sensing letters, 2 (3): 315-318.

Batista, G.; Shimabukuro, Y.E.; Lawrence, W.T. 1997. The longterm monitoring of vegetation cover in the Amazon region of northern Brazil using NOAA-AVHRR data. International Journal of Remote Sensing, 18 (15): 3195-3210.

Câmara, G; Souza, R.C.M.; Freitas, U.M.; Garrido, J. 1996. SPRING: Integrating remote sensing and GIS by object-oriented data modelling. Computers \& Graphics, 20 (3): 395-403.

Diner, D.J.; Martonchilk, J.V. 1985. Influence of aerosol scattering on atmospheric bluring of surface features. IEEE Transaction on Geoscience and Remote Sensing, 23: 618-624.

Domenikiotis, C.; Dalezios, N.R.; Loukas, A.; Karteris, M. 2002. Agreement assessment of NOAA/AVHRR NDVI with Landsat TM NDVI for mapping burned forested areas. International Journal of Remote Sensing, 23 (20): 4235-4246.

FEMA-MT (Fundação Estadual do Meio Ambiente). Sistema de detecção de focos de calor. Cuiabá., 2003. Relatório Anual. 23Pp.

Fraser, R.H.; Li, Z. Estimating fire-related parameters in boreal forest using SPOT VEGETATION. 2002. Remote Sensing of Environment, 82 (1): 95-110.
Giglio, L.; Descloitres, J.; Justice, C.O.; Kaufman, Y.J. 2003. An enhanced contextual fire detection algorithm for MODIS. Remote Sensing of Environment, 87 (2-3):273-282.

Gitas, I.Z.; Mitri, G.H.; Ventura, G. 2004. Object-based image classification for burned area mapping of Creus Cape, Spain, using NOAA-AVHRR imagery. Remote Sensing of Environment, 92 (3): 409-413.

Grace, J. 2004. Understanding and managing the global carbon cycle. Journal of Ecology, 92 (2): 189-202.

Gregoire, J.M.; Tansey, K.; Silva, J.M.N. 2003. The GBA2000 initiative: Developing a global burned area database from SPOT-VEGETATION imagery. International Journal of Remote Sensing, 24 (6): 1369-1376.

Huete, A.R.; Justice, C.; van Leeuwen, W. 1999. MODIS vegetation index (MOD13) algorithm theoretical basis document. [online]. 3: 1-142. <modis-land. gsfc.nasa.gov/ pdfs/atbd_mod13.pdf $>$. Visitado em (7 novembro 2002).

Huete, A.; Liu, H.Q.; Batchily, K.; van Leeuwen, W. 1997. A comparison of vegetation indices over a global set of TM images for EOS-MODIS. Remote Sensing of Environment, 59: 440-451.

Huete, A.; Justice, C.; Liu, H. 1994. Development of vegetation and soil indices for MODIS-EOS. Remote Sensing of Environment, 59: 224- 234.

Houghton, R. A. 1995. Determining emissions of carbon from land: A global strategy. Toward Global Planning of Sustainable Use of the Earth. Development of Global Eco-Engineering . Elsevier Science B.V., Amsterdam, The Netherlands. p. 59 . 76.

INPE (Instituto Nacional de Pesquisas Espaciais). 2005. Monitoramento da floresta Amazônica brasileira por satellite. Seminário de avaliação. Disponivel on-line: <http:// www.obt.inpe.br/prodes/seminario2005/> (Acessado em 12 de Agosto de 2005)

IPCC (Intergovernmental Panel on Climate Change). Technologies, policies and measures for mitigating climate change. IPCC Technical Paper I. 1996. Disponivel on-line: $<$ http://www.ipcc.ch/pub/IPCCTP.I(E).pdf > (Acessado em 12 de Agosto de 2005).

Justice, C.O.; Giglio, B.; Korontzi, S.; Owens, J.; Morisette, J.T.; Roy, D.P.; Descloitres, J.; Alleaume, S.; Petitcolin, F.; Kaufman, Y. 2002. The MODIS fire products. Remote Sensing of Environment, 83: 244-262.

Lashof, D.A. 1996. The contribution of biomass burning to global warming: an integrated assessment. In: Levine, J.S. (Ed) Global biomass burning. MIT Press. Cambridge, p. 441-444.

Levine, J.S.; Wesley III, R.C.; Winstead, E.L.; Thinehart, R.P.; Cahoon Jr., D.R.; Sebacher, D.K.; Sebacher, S.; Stocks, B.J.1996. Biomass burning: combustion emissions, satellite imagery, and biogenic emissions. In Levine J.S. (Ed) Global biomass burning. MIT Press. Cambridge, p. 264-271. 


\section{ACTA AMAZONICA}

DETECÇÃO DE CICATRIZES DE ÁREAS QUEIMADAS BASEADA NO MODELO LINEAR DE MISTURA ESPECTRAL E IMAGENS ÍNDICE DE VEGETAÇÃO UTILIZANDO DADOS MULTITEMPORAIS DO SENSOR MODIS/TERRA NO ESTADO DO MATO GROSSO, AMAZÔNIA BRASILEIRA
Lombardi, R.J.R. 2003. Estudo da recorrência de queimadas e permanência de cicatrizes do fogo em áreas selecionadas do cerrado brasileiro, utilizando imagens TM/LANDSAT. Dissertação de Mestrado em Sensoriamento Remoto. INPE. São Jose dos Campos . INPE-12663-TDI/1006, 172 p.

Li, Y.; Vodacek, A.; Kremens, R.L.; Ononye, A.; Tang, C. 2005. A bybrid contextual approach to wildland fire detection using multispectral imagery. IEEE Transactions on Geoscience and Remote Sensing, 43 (9)2115-2126.

MCT (Ministério da Ciência e Técnologia). 2004. Emissões e Remoções de Dióxido de Carbono por Conversão de Florestas e Abandono de Terras Cultivadas. Primeiro inventário brasileiro de emissões antrópicas de gases de efeito estufa: Relatórios de referência. 2004. Disponivel online: http://www.mct.gov.br/clima/comunic_old/ floresta1.htm (Acessado em 12 de Agosto de 2005).

Nimer, E. 1977. Geografia do Brasil. Região Centro-Oeste. Rio de Janeiro: IBGE, $364 \mathrm{p}$.

Page, S.E.; Siegert, F.; Rieley, J.O.; Boehm, H.D.V.; Jaya, A.; Limin, S. 2002. The amount of carbon released from peat and forest fires in Indonesia during 1997. Nature, 420: 61-65.

Pereira, J.M.C. A comparative evaluation of NOAA/AVHRR vegetation indexes for burned surface detection and mapping. 1999. IEEE Transactions on Geoscience and Remote Sensing, 37 (1): 217 - 226.

Pereira, A.C.; Setzer, A.W. 1996. Comparison of fire in savannas using AVHRR's Channel 3 and TM images. International Journal of Remote Sensing, 17 (10): 1925-1937.

Pergola, N.; Marchese, F.; Tramutoli, V. 2004. Automated detection of thermal features of active volcanoes by means of infrared AVHRR records. Remote Sensing of Environment, 43 (9): 2115-2126.

Razafimpanilo, H.; Frouin, R.; Iacobellis, S.F.; Somerville, R.C.J. 1995. Methodology for estimating burned area from AVHRR reflectance data. Remote Sensing of Environment, 54: 273289.

Roy, D.P.; Lewis, P.E.; Justice, C.O. 2002. Burned area mapping using multi-temporal moderate resolution data - a bidirecional reflectance model-based expectation approach. Remote Sensing of Environment, 83: 263-286.

Sá, A.C.L; Pereira, J.M.C.; Vasconcelos, M.J.P.; Silva, J.M.N; Ribeiro, N.; Awasse, A. 2003. Assessing the feasibility of sub-pixel burned area mapping in miombo woodlands of northern Mozambique using MODIS imagery. International Journal of Remote Sensing, 24:1783-1796.

Silva, J.M.N.; Sá, A.C.L.; Pereira, J.M.C. 2005. Comparison of burned area estimates derived from SPOT-VEGETATION and Landsat ETM+ data in Africa: Influence of spatial pattern and vegetation type. Remote Sensing of Environment, 96 (2): 188-201.

Shimabukuro, Y.E.; Smith, J.A. 1991. The least-square mixing models to generate fraction images derived from remote sensing multispectral data. IEEE Transactions on Geoscience and Remote Sensing, 29 (1): 16-20.

Small, C. 2003. High spatial resolution spectral mixture analysis of urban reflectance. Remote Sensing of Environment, 88:170186.

Sousa, A.M.O.; Pereira, J.M.C.; Silva, J.M.N. 2003. Evaluating the performance of multitemporal image compositing algorithms for burned area analysis. International Journal of Remote Sensing, 24 (6): 1229-1236.

Stropiana, D.; Tansey, K.; Gregoire, J.M.; Pereira, J.M.C. 2003. An algorithm for mapping burnt areas in Australia using SPOTVEGETATION data. IEEE Transactions on Geoscience and Remote Sensing, 41 (4): 907 - 909.

Zhan, X.; Sohlberg, R.A.; Townshend, J.R.G.; DiMiceli, C.; Carroll, M.L.; Eastman, J.C.; Hansen, M.C.; DeFries, R.S. 2002. Detection of land cover changes using MODIS $250 \mathrm{~m}$ data. Remote Sensing of Environment, 83 (2): 336-350.

\section{RECEBIDO EM 21/02/2005 ACEITO EM 01/11/2005}

